\title{
Analysis of Single-Diode PV Model and Optimized MPPT Model for Different Environmental Conditions
}

\author{
S. Senthilkumar $\mathbb{D}^{1},{ }^{1}$ V. Mohan $\mathbb{D}^{2},{ }^{2}$ S. P. Mangaiyarkarasi $\mathbb{D}^{3},{ }^{3}$ and M. Karthikeyan ${ }^{4}$ \\ ${ }^{1}$ Department of Electronics and Communication Engineering, E.G.S. Pillay Engineering College, Nagapattinam, \\ Tamilnadu, India \\ ${ }^{2}$ Department of Electrical and Electronics Engineering, E.G.S. Pillay Engineering College, Nagapattinam, \\ Tamilnadu, India \\ ${ }^{3}$ Department of Electrical and Electronics Engineering, University College of Engineering, Panruti Campus, \\ Panruti, Tamilnadu, India \\ ${ }^{4}$ Department of Electrical and Electronics Engineering, University College of Engineering, Pattukkottai Campus, Pattukkottai, \\ Tamilnadu, India
}

Correspondence should be addressed to S. Senthilkumar; senthil.lanthiri@gmail.com

Received 30 September 2021; Revised 4 November 2021; Accepted 23 November 2021; Published 31 January 2022

Academic Editor: Sudhakar babu T

Copyright (c) 2022 S. Senthilkumar et al. This is an open access article distributed under the Creative Commons Attribution License, which permits unrestricted use, distribution, and reproduction in any medium, provided the original work is properly cited.

\begin{abstract}
The performance of photovoltaic (PV) systems must be predicted through accurate simulation designs before proceeding to a realtime application to avoid errors. However, predicting the cohesive relationship between current and voltage and estimating the parameters of a single diode model become a perplexing task due to insufficient data in the datasheet of PV panels. This research work presents single-diode solar PV system simulation analysis under different conditions, and the performance is improved by introducing an optimization-based maximum power point tracking (MPPT) strategy. Before simulation, a mathematical model for a single diode and optimization approaches are presented in this research work. Particle swarm optimization (PSO), genetic algorithm (GA), BAT optimization, and grey wolf optimization (GWO) model-based MPPT circuits are designed, and the performances are comparatively analyzed. The simulation results identify the nonlinear relationship between current and voltage and between power and voltage as characteristic curves for different temperature and irradiance values. For maximum power $\left(P_{\max }\right)$, the maximum peak point tracking power and efficiency are analyzed to verify the optimization-based MPPT system. The simulation results demonstrate that the GWO model obtains a maximum tracking efficiency (TE) of $98 \%$, which is much better than that of other optimization techniques.
\end{abstract}

\section{Introduction}

Among all renewable energy sources, solar-based power generation gains more attention due to its inexhaustible and clean energy characteristics. The conversion of energy, i.e., sunlight to electricity, can be obtained directly using PV cells or a combination of concentrated solar power systems. Solar power generation prominently helps to minimize the emissions from fossil fuel-based power generation [1]. Wind energy-based power generation systems also contribute better energy and reduce fossil fuel requirements. Wind energy is seasonally dependent, and it can produce more energy at a particular time [2]. But the abundant availability and seasonal-independent characteristics of solar energybased systems make them perform better than wind energybased systems [3]. High-quality ac output with reduced lower order harmonics and total harmonic distortion can be synthesized from the PV modules using multilevel inverters [4-7]. The power generated by solar PV systems can be transferred through grids, which is equal to the power generated through thermal power plants $[8,9]$. Though the power generation of solar power systems is better, their implementation cost is quite high. So, it is essential to measure the reliability and power generation accuracy of the 
solar power systems before installation. Simulation environments are used to measure the performance so that errors can be avoided and performance can be improved upon implementing in real time.

In the design procedure of solar PV cells, a thin wafer of semiconductors and a p-n junction diode are used. Electricity has been generated by converting solar radiation by fabricating the diode into the cell wafers [10]. Characteristics of semiconductors are the key feature of the PV process. The photons from sunlight have higher energy than the semiconductor band gap energy. Due to this, electron-hole pairs are created in the cell. The pair generation is directly proportional to solar irradiance, and it is isolated by the $\mathrm{p}-\mathrm{n}$ junction internal electric field. Due to this process, photocurrent is generated and solar radiation acts as the most important part of the energy generation process. The dc power generated from solar panels is converted into ac power as load using novel control strategies $[11,12]$. The characteristics of PV cells such as I-V and P-V are nonlinear due to cell temperature, solar radiation, and other parameters. Typically, solar cells are assembled using silicon, and due to low conversion efficiency, the generated power will be inadequate $[13,14]$. So, it is essential to analyze and improve the conversion efficiency of the PV systems through efficient cell modeling.

Cell modeling is directly related to accuracy, which represents the PV system characteristics [15]. To obtain a desired current and voltage from a solar panel, a series or parallel combination of cells is generally used. However, the performance can be affected by temperature, solar radiation, etc.; due to this, simulation of solar panels becomes crucial. Generally, a comprehensive investigation is followed to measure the performance of solar PV models [16, 17]. Different parametric models are presented by researchers such as the single-diode model and two-diode model [18]. Among all, the single-diode model is widely preferred as the performance matches the real-time solar cell performance [19-21]. The single-diode model is alternatively called the five-parameter model, and its design includes a parallel connection of ideal diode and current source with bypassed shunt resistance. Single-diode model solar cell parameters can be efficiently analyzed to improve the performance of PV systems. The single-diode model has more benefits in terms of parameters such as minimum error I-V and P-V curves, and a simple and easy implementation provides better results similar to manufacturer's results [22].

The major contributions of this research work are as follows:

(i) A single-diode model is developed for solar PV systems under different environmental conditions

(ii) For the achieved single-diode solar PV model, different optimization techniques are presented for MPPT

(iii) Comparative analysis of different optimization models is performed to find an appropriate technique for MPPT

This research work is structured as follows. In Section 2, a review of existing research works is presented. In Section 3, detailed mathematical formulations are presented for the proposed solar PV model and MPPT. In Section 4, experimental results and their observations are presented. Finally, in Section 5, the conclusion and future scope are presented.

\section{Related Works}

A vast survey of existing research works on solar PV systems and their feature merits, demerits, and applications is discussed in detail in this section. Researchers pay more attention to analyze the performance of single-diode solar PV models in various research works. The parameters are estimated through characteristic equations, and extracting relevant optimal parameters from the manufacturer's datasheet is quite complex [23]. Also, it is difficult to obtain the parameters of a PV model from the current-voltage characteristics due to its implicit nature. The power-law system characterizes the PV module's I-V properties. Different operating incidences are considered to predict the electrical characteristics, which do not require any iterative or nonelementary functions. Reduced computational complexity and cost are the major features of the power-law model [24]. The parameters such as irradiance and temperature are considered, and the parameters of the singlediode, double-diode, and triple-diode PV systems are evaluated for different conditions [25-27]. Combining the analytical equations and pattern search algorithm, the I-V characteristics are analyzed with maximum accuracy, which is the feature merit of research work. However, the computational complexity is quite high due to the long training process.

The reduced space search approach efficiently estimates the parameters of the single-diode model [28]. The no convex nature of the optimization problem is eliminated through the space search approach. Due to this, the computational complexity in parameter estimation is reduced and high-quality solutions are obtained without user intervention. The performance of parameter estimation of PV modules is improved by converting no convex optimization problems into convex optimization problems using a modified barrier function [29]. The optimal values are obtained using an adaptive identification technique, which provide a unique solution to improve the precision of electrical parameters. The relationship between operating conditions and electrical parameters utilizes the thermal coefficient of power to evaluate the performance of the PV cell [30]. The impact of energy production due to changes in the operating point and the disconnected array is reduced, which obtains $P_{\max }$ for the temperature and irradiance.

Shunt resistance was evaluated from a mathematical model based on the manufacturer's datasheet information [31]. The balance between computation time and accuracy is demonstrated to validate the shunt PV module. Evaluation of series resistance for a single-diode PV module presents a comparative analysis of different techniques [32]. The systematic analysis describes the feature merits and demerits of series resistance parameter estimation techniques in terms of accuracy and reliability. A voltage-dependent temperature 
coefficient is considered for $\mathrm{I}-\mathrm{V}$ parameter estimation of a single-diode model [33]. Series resistance is obtained to get improved accuracy for different temperature ranges. Accurate estimation of the solar PV parameters for single diode and double diode models depends on solar irradiance, temperature, and values from solar PV datasheet. Improved precision is obtained for different irradiance and temperatures that increase the voltage range as well as $P_{\max }$ point extraction.

The explicit nonlinear model presents a generalized perunit-single-diode model for a PV system to extract the I-V characteristics [34]. The nonlinear least-square fit technique utilized in this research work extracts the three parameters, and it is refined using the per-unit-single-diode model to extract five parameters. After MATLAB programming is over and done with, the demonstration is presented to depict the minimum computational cost. A data-driven model includes feature extraction techniques to extract essential information from a large volume of I-V data [35]. Three different sources are considered with different data point densities to generate the single-diode PV module's I-V characteristics, which make the approach suitable for timeseries performance evaluation. RStudio is used to demonstrate the feature extraction process and power degradation mechanisms in the PV module [36].

Computation of the average cell temperature of PV modules is reported, which discusses the limitations in the temperature measurement process [37]. Conventional computational models ignore the sensor temperatures, which are from the backside of the PV module. However, they will establish a temperature gradient that affects the parameter evaluation performance. Using standard test conditions and translational formulas, the factors that affect the performance are identified. Different temperature and irradiation levels are considered to define the high degree of accuracy in the evaluation process.

In solar-based power generation, another important factor that must be considered to improve the conversion efficiency and power generation is MPPT. MPPT is used to track solar irradiance, and various MPPT techniques are introduced by researchers in the recent era [38]. The literature analysis presents a detailed analysis of MPPT techniques [39]. The nonuniform solar irradiance condition is considered to analyze hybrid techniques, and online, uniform irradiance is considered for offline conditions. The electrical characteristics of the PV system and MPPT estimation process utilize a series of analytical equations under partial and uniform shading conditions [40-42]. Research work accurately evaluates the I-V characteristics and improves the MPPT efficiency. Similarly, the MPPT estimation model processes the PV current and voltage characteristics and eliminates oscillations in the power point tracking process [43]. The estimation loss is reduced and estimation speed is increased for the evaluation procedure of the singlediode model.

The major factor that needs to be considered for MPPT models is their tracking accuracy and tracking speed. It is essential to introduce a better tradeoff between cost and performance for the MPPT methods. The perturb and observe method utilizes the local irradiance data to determine the offline conditions [44]. The perturbation step size is optimized based on the analysis results of the support vector machine model. This process improves the system performance without any complex control circuits. An adaptive neurofuzzy inference system and PSO methods are combined as a hybrid MPPT model to obtain maximum PV power [45]. The hybrid approach provides maximum TE with zero oscillations, and it does not require any extra sensor arrangements to measure the temperature and irradiance parameters. An adaptive fuzzy logic-based MPPT model improves the adaptive skills of conventional fuzzy logic-based techniques [46]. The operating point of existing methods varies due to temperature and irradiance in realtime conditions, which introduces slow convergence and poor accuracy in the results. The adaptive method eliminates such practical limitations and improves accuracy with faster convergence under dynamic conditions.

Recently, various optimization models are introduced for MPPT. Among all, PSO gains more attention, and numerous research works are evolved to enhance the tracking performance of PV systems [47]. However, conventional PSO-based MPPT methods' efficiency decreases because of several peaks in the PV curves that occur due to partially shaded conditions. Modified PSO is used to eliminate this limitation and to improve efficiency, which increase the output power under nonuniform irradiation level and partial shading conditions [48, 49]. The dynamic PSO model considers the converter topology and solar panel configurations to select the parameters for the PSO model, which provides optimal sampling time for MPPT [50].

Though PSO-based MPPT techniques are evolved for efficiency improvement, they face difficulties while extracting global parameters. Other than PSO, few other optimization models are introduced such as the flower pollination algorithm [51], the Lipschitz optimization MPPT algorithm [52], artificial bee colony optimization [53], and the perturb and observe algorithm [54] for MPPT. From the literature analysis, it could be observed that the single-diode model is widely used for solar PV modules. The performance of the single-diode model is more reliable and accurate than that of other models. For MPPT, the PSO model is widely used. However, it faces issues while extracting global parameters that affect the accuracy. Considering these observations, this research work presents an analysis of a single-diode model under different conditions and an optimization model for MPPT. The performance of the overall system is verified under different environmental conditions for better results.

\section{Proposed Work}

Solar PV cells are made from semiconducting materials. Different manufacturing processes are followed to design the PV cells. The working of PV cells is based on the PV effect that generates a potential difference in the junction of $p-n$ in response to radiation or visible light. The basic structure of 
silicon-based PV cells includes a thin layer of bulk silicon or a thin film of Si that is connected to electric terminals. Also, a metallic grid is connected to the semiconductor top surface, while a thin semiconductor layer is specially treated to obtain a p-n junction. Depending on the necessity, a series or parallel combination of PV models is used. When the module is exposed to light, the charge carriers are generated, while the semiconductor absorbs the photons from the light. The electric field in the $\mathrm{p}-\mathrm{n}$ junction separates the carriers so that an electric current will start to flow through the external circuit. The working procedure is similar to the $\mathrm{p}-\mathrm{n}$ junction diode if the PV effect is removed. Based on this, the current flow of the PV module is obtained from the diode current equation, and it is given as

$$
I_{d}=I_{o}\left(e^{V_{d} / n N_{s} V_{t}}-1\right)
$$

where $V_{d}$ is the potential difference, $I_{o}$ is the reverse saturation current, $V_{t}$ is the thermal voltage, and $N_{s}$ is the number of series-connected cells. The diode ideality factor is represented as $n$. The thermal voltage is obtained from the Boltzmann constant and electron charge as $V_{t}=k T / q$, where $k$ is the Boltzmann constant and $q$ represents the electron charge whose values are $1.380650 \times 10^{-23} \mathrm{~J} / \mathrm{K}$ and $1.602176 \times 10^{-19} \mathrm{C}$, respectively, and $T$ is the temperature.

The characteristics of ideal solar PV cells are represented based on current generation. However, the generated current gets diverted from its ideal characteristics due to optical and electrical losses. The ideal model does not consider the effects of resistance, and its output is represented as

$$
I=I_{p g}-I_{d}
$$

where $I_{p g}$ is the current generated by the PV effect and $I_{d}$ is the diode current. For ideal analysis, the diode current equation is represented using the Shockley equation, and it is given as

$$
I_{d}=I_{s}\left(e^{V_{d} / n V_{t}}-1\right),
$$

where $V_{d}$ is the potential difference of the diode, $I_{s}$ is the diode saturation current, and $V_{t}$ is the thermal voltage, which is given as $V_{t}=k T / q$, and the ideal solar PV final current is given as

$$
I=I_{p g}-I_{s}\left(e^{q V_{d} / n k T}-1\right) .
$$

However, ideal models fail to establish a better and accurate relationship between voltage and current of the cells. This happens because the analysis does not consider the internal resistance effects. The practical single-diode PV model consists of series resistance and shunt resistance to get a better relationship among the cell parameters. Single-diode models are simple and efficient, but they have constraints for temperature variations. Figure 1 depicts an illustration of a single-diode PV circuit.

The current flow due to metal-semiconductor contact and resistance due to impurity concentration are observed as series resistance. The shunt resistance indicates the leakage current across the junction that is parallel to the diode.

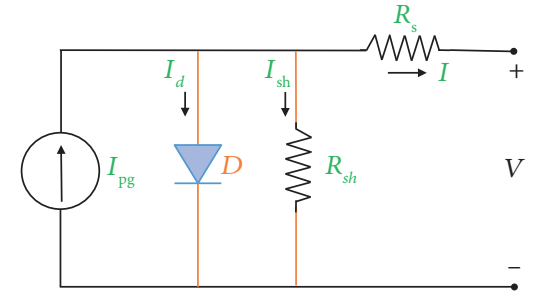

FIgURE 1: Single-diode solar cell equivalent circuit.

Mathematically, the above circuit output current is obtained from equation (2) as

$$
I=I_{p g}-I_{d}-\frac{V_{d}}{R_{s h}},
$$

where the diode voltage $\left(V_{d}\right)$ is obtained from the summation of actual input voltage $(\mathrm{V})$ and the voltage across the series resistance as $V_{d}=V+I R_{s}$. However, the shunt and series resistance will introduce an impact on the I-V characteristics of the PV device. Series resistance has an impact on the output voltage, and shunt resistance has an impact on current. So, the above equation is modified to obtain a single-diode model, and the current is expressed as

$$
I=I_{p g}-I_{s}\left(e^{q V_{d} / n k T}-1\right)-\frac{V+I R_{s}}{R_{s h}} .
$$

The I-V and P-V characteristics of the single-diode model are depicted in Figures 2(a) and 2(b), respectively.

To calculate the values of series and shunt resistance, the current $I_{p g}$ from equation (5) is reformulated as follows:

$$
I_{p g}=I_{s}\left(\frac{R_{s}+R_{s h}}{R_{s h}}\right) .
$$

By substituting the above equation in (6), the shunt resistance can be obtained as a function of series resistance as follows:

$$
R_{s h}=\frac{I_{s} R_{s}-V_{m}-I_{m} R_{s}}{I_{m}+I_{s a t}\left(e^{V_{d} / n k T}-1\right)-I_{s}},
$$

where $V_{m}$ and $I_{m}$ are the voltage and current at the maximum power point. From the above equation, the maximum series resistance value can be obtained by neglecting the denominator terms, and the series resistance is expressed as

$$
R_{s}=\frac{n k T \ln \left(\left(I_{s}-I_{m}\right) / I_{s a t}-1\right)-V_{m}}{I_{m}} .
$$

In the parameter estimation process, the details of solar cell I-V characteristics are analyzed under different temperatures and irradiation. The iterative procedure obtains the parameters on every iteration. The proposed model does not utilize any optimization techniques and other extraction techniques to obtain the parameters that are the novelty of this research work. From equation (6), the load current is obtained as

$$
I_{l}=I_{p g}-I_{s}\left(e^{q\left(V+I_{l} R_{s}\right) / n k T}-1\right)-\frac{V+I R_{s}}{R_{s h}} .
$$




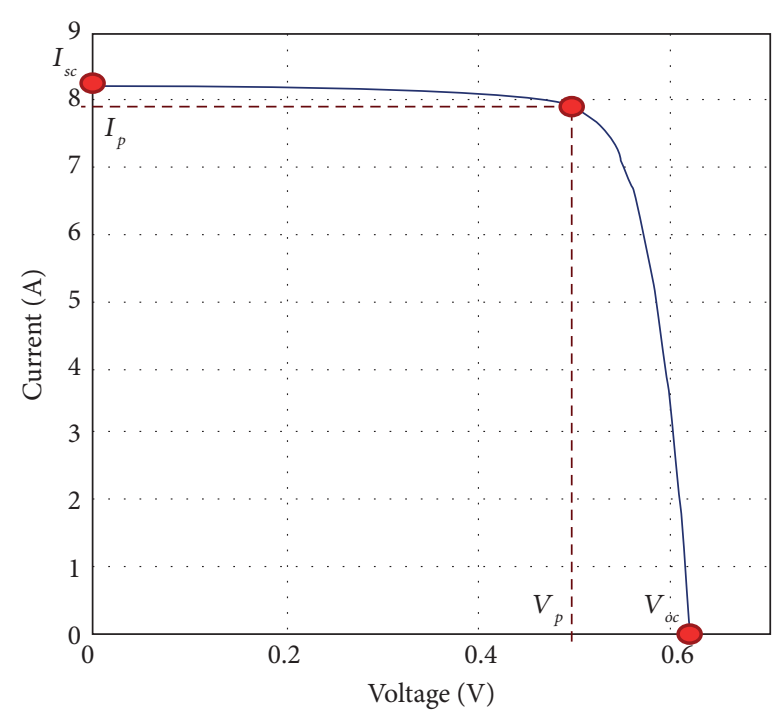

(a)

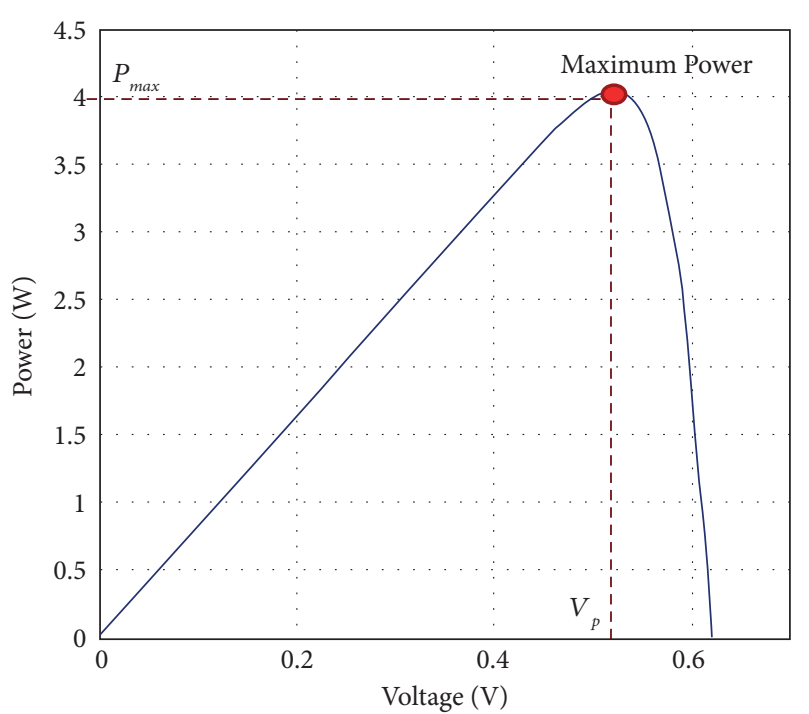

(b)

Figure 2: Characteristics of the PV cell: (a) I-V characteristics; (b) P-V characteristics.

Assume the voltage is fixed at the load side and the derivative of current $I_{l}$ with respect to PV current is given as

$$
\frac{\partial I_{l}}{\partial I_{p g}}=1-\frac{q R_{s} I_{s}}{n k T}\left(e^{q\left(V+I R_{s}\right) / n k T}\right) \frac{\partial I_{l}}{\partial I_{p g}}-\frac{R_{s}}{R_{s h}} \frac{\partial I_{l}}{\partial I_{p g}} .
$$

The above expression can be expressed finally as

$$
\frac{\partial I_{l}}{\partial I_{p g}}=\left[1+\frac{q R_{s} I_{s}}{n k T}\left(e^{q\left(V+I R_{s}\right) / n k T}\right)+\frac{R_{s}}{R_{s h}} \frac{\partial I_{l}}{\partial I_{p g}}\right]^{-1} .
$$

The other parameters are obtained in the same manner, and they are given in the following equations:

$$
\begin{aligned}
& \frac{\partial I_{l}}{\partial I_{s}}=\left[1-\left(e^{q\left(V+I R_{s}\right) / n k T}\right)\right] \frac{\partial I_{l}}{\partial I_{p g}}, \\
& \frac{\partial I_{l}}{\partial n}=\left[I_{s} \frac{q\left(V+I_{l} R_{s}\right)}{n^{2} k T}\left(e^{q\left(V+I_{l} R_{s}\right) / n k T}\right)\right] \frac{\partial I_{l}}{\partial I_{p g}}, \\
& \frac{\partial I_{l}}{\partial R_{s}}=-\left[I_{s} \frac{q\left(I_{l}\right)}{n k T}\left(e^{q\left(V+I_{l} R_{s}\right) / n k T}\right)+\frac{I_{l}}{R_{s h}}\right] \frac{\partial I_{l}}{\partial I_{p g}} .
\end{aligned}
$$

Similar to the above process, the output voltage parameters are obtained from equation (7) by assuming the load current is fixed, and they are expressed as

$$
\begin{aligned}
& \frac{\partial V_{l}}{\partial I_{p g}}=R_{s h}\left[1+\frac{q R_{s h} I_{s}}{n k T}\left(e^{q\left(V+I R_{s}\right) / n k T}\right)\right]^{-1}, \\
& \frac{\partial V_{l}}{\partial I_{s}}=\left[1-\left(e^{q\left(V+I R_{s}\right) / n k T}\right)\right] \frac{\partial V_{l}}{\partial I_{p g}}, \\
& \frac{\partial V_{l}}{\partial n}=\left[I_{s} \frac{q\left(V+I_{l} R_{s}\right)}{n^{2}}\left(e^{q\left(V+I_{l} R_{s}\right) / n k T}\right)\right] \frac{\partial V_{l}}{\partial I_{p g}},
\end{aligned}
$$

$$
\frac{\partial V_{l}}{\partial R_{s h}}=\frac{1}{R_{s h}}\left[I_{p g}+I_{s}\left(1-e^{q\left(V+I_{l} R_{s}\right) / n k T}\right)-I_{l}\right] \frac{\partial I_{l}}{\partial I_{p g}} .
$$

The current and voltage points in the curve can be moved vertically using the approximation process, and the change in current and voltage points is given as $\Delta I_{l}(i)$ and $\Delta V_{l}(i)$, respectively. However, the nonlinear output voltage and current characteristics are directly proportional to irradiance, load current, and temperature. So, it is essential to introduce an MPPT system for the solar PV module. From the I-V and P-V characteristics of a PV system, it can be observed that maximum current is obtained in the absence of shunt and series resistance. By short circuiting the resistance, the maximum current is obtained as $I_{s c}$, whereas the voltage is zero when the PV module is short circuited. If there is a break in the circuit, an open-circuit voltage $\left(V_{o c}\right)$ will occur and resistance will become high, which reduces the current. The knee point where $P_{\max }$ is obtained is given as the $P_{\max }$ point, and the voltage and current at this point are given as $V_{p}$ and $I_{p}$. In the proposed work, four optimization models are introduced for MPPT, and the performances are compared to obtain a better model. Existing techniques acquire the maximum power point or obtain the diode model parameters using optimization techniques or the mathematical model. In the case of proposed work, the parameters are extracted without any special optimization techniques; instead, the optimization model is used to attain better performances in terms of tracking efficiency, maximum power, and maximum power point tracking. A short description of optimization models is presented in the following section.

3.1. Particle Swarm Optimization. The PSO is a stochastic technique that is formulated based on the bird's flocking 
characteristics when it searches for food. Initially, a random population is initiated as particles, and each particle carries some information about the search space, which is exchanged with other particles in $\mathrm{P}$. The best solution is considered the global best, and other particles are starting to move towards the best particle solution. The trajectory of movement will be based on the best solution, and this process is repeated until it meets the stopping criteria. The current and previous velocity values are held by each particle so that the next best position can be obtained on every iteration. The velocity and position vectors of each particle are updated as follows:

$$
x_{i j}^{t+1}=x_{i j}^{t}+v_{i j}^{t+1},
$$

where $x_{i j}^{t}$ is the position vector of the $i^{\text {th }}$ particle at iteration $t$ and $x_{i j}^{t+1}$ is the position vector of the $i^{\text {th }}$ particle at iteration $t+1$, while the velocity is given as

$$
v_{i j}^{t+1}=\omega v_{i j}^{t}+c_{1} r_{1}\left(\text { pbest }_{i j}^{t}-x_{i j}^{t}\right)+\left(c_{2} r_{2} g b e s t^{t}-x_{i j}^{t}\right),
$$

where $v_{i j}^{t+1}$ is the velocity vector of the $i^{\text {th }}$ particle at iteration $t+1$ and $c_{1}$ and $c_{2}$ are the coefficients. The random numbers that are distributed uniformly in the range $[0,1]$ are represented as $r_{1}$ and $r_{2}$. The best fitness values for the particle are considered pbest, and gbest represents the fitness value for all the particles. The position of each particle has been evaluated based on this fitness function, and it is given as

$$
f=\left(x_{i j}^{t}-v_{\max }\right)^{2}+\left(x_{i j}^{t}-i_{\max }\right)^{2} .
$$

To update the pbest and gbest positions, the fitness function of each particle is compared. If the present position is comparatively better than the previous position, then the present position is considered the best value, and the overall fitness function is also updated based on that. Mathematically, it is formulated as

$$
\begin{aligned}
\text { pbest }_{i j}^{t} & = \begin{cases}x_{i j}^{t}, & \text { if } f\left(x_{i j}^{t}\right)<\text { pbest }_{i j}^{t}, \\
\text { pbest }_{i j}^{t}, & \text { otherwise, }\end{cases} \\
\text { gbest }_{i j}^{t} & =\min \left(\text { pbest }_{j}^{t}, \text { pbest }_{j+1}^{t}, \ldots, \text { pbest }_{s}^{t}\right) .
\end{aligned}
$$

To update the position and velocity of all the particles, the above equations are used and the same procedure is implemented to obtain the MPPT process. The position of the panel is adjusted for every iteration, and the best position is updated so that $P_{\max }$ can be tracked during the power generation process. In the proposed work, the values of $c_{1}$ and $c_{2}$ are considered 2 and 1.5, respectively. The weight factor $\omega$ is taken as 1.2, and the values of $r_{1}$ and $r_{2}$ are taken in the range of $[0,1]$.

3.2. Genetic Algorithm Optimization. The GA was introduced to solve constrained and unconstrained optimization issues. Based on natural selection and biological evolution, the problems are solved in the GA. The individual solutions in the GA are modified continuously, and next generations are produced by selecting a random individual from the current $P$. On successive evolution, the optimal solution is obtained in the GA. Objective functions that are stochastic, discontinuous, nonlinear, and nondifferentiable can be efficiently solved by a GA. Genetic algorithm-based MPPT identifies the optimal parameter based on the survival of fittest principle. Three basic operators considered in the GA are selection, crossover, and mutation. In this, the selection operator defines the selection of materials from the present generation that is suitable for the next generation. Generally, the fitness parameter is used to select the materials. The crossover operator produces new materials by combining two chromosomes, and the mutation operator helps to maintain the genetic diversity of each generation. To get better convergence, the first $\mathrm{P}$ is reset into the initial condition when there is a variation in irradiance and temperature. The reinitialization is obtained based on the following two conditions:

$$
\begin{array}{r}
|v(k+1)-v(k)|<\Delta v, \\
\left|\frac{\left(p_{p v}(k+1)-p_{p v}(k)\right)}{p_{p v}(k)}\right|>\Delta p,
\end{array}
$$

where $v$ is the output voltage and $p_{p v}$ is the power of the PV system. For each iteration, the initial $P$ and their individuals are applied, and the initial position of $P$ is given as

$$
\left[P_{1}, P_{2}, P_{3}, P_{4}, P_{5}\right]=[1.0,0.8,0.6,0.4,0.2] V_{o c} \text {. }
$$

The generated power $p_{p v}(k)$ at the kth iteration is considered the fitness function. The crossover operator function combines the two chromosomes to obtain a new child, and it is given as

$$
\begin{gathered}
c(k)=\operatorname{rp}(r)-((1-r) p(k+1)), \\
c(k+1)=((r-1) p(k))-((r) p(k+1)),
\end{gathered}
$$

where $c(k)$ is the next-generation solution and $r$ is the random number. To obtain the relationship between the duty cycle $(D)$ and the output voltage, the ratio of nextgeneration solution and open-circuit voltage is considered. Due to the sequential aspect of chromosomes, the dynamic response and mutation impact on convergence are considered in the genetic model. $c(k)$ and the random number $r$ are selected in the range $[0,1]$, and the position values are taken in the range $[0.2,1.0]$.

3.3. BAT Optimization. BAT optimization is a nature-inspired optimization algorithm that is formulated based on the echolocation features of bats' food-searching process. Using echolocation, the insects are identified by bats so that the food sources are identified. The intensity of the return signal and its direction are the major factors to locate the prey in the optimization model. The ultrasonic pulses are emitted at a certain amplitude and rate, and a bat receives its own signal as feedback in between the pulse trains to interpret the prey location. Depending on the feedback intensity, the distance is measured. If the intensity is high, the 
prey is near the bat and it moves towards the prey by intensifying the pulse amount to capture the prey. The flying characteristics of bats are random with velocity $\left(v_{i}\right)$, and its position and loudness are given as $x_{i}$ and $l_{i}$. The emission rate of bats is considered in the range $[0,1]$ depending on the target proximity. The velocity and position of the bat at each step are formulated as

$$
\begin{aligned}
& x_{i}^{t+1}=x_{i}^{t}+v_{i}^{t+1}, \\
& v_{i j}^{t+1}=v_{i}^{t}+\left(x_{i}^{t}-x^{*}\right) f_{i},
\end{aligned}
$$

where $f_{i}$ is the randomly assigned frequency that is given as

$$
f_{i}=f_{\min }+\left(f_{\max }-f_{\min }\right) \varphi
$$

where $\varphi$ is the random vector for uniform distribution that is in the range $[0,1]$ and $x^{*}$ is the global best position that is obtained by comparing all the solutions at each iteration. In the position update process, the pulse emission rate is considered. If the random vector is greater than the emission, then the exploitation stage is selected. The current position is replaced based on the solution obtained in the local search process, and it is given as

$$
x_{n}=x^{*}+l^{t}
$$

where the random number is obtained from Gaussian distribution or uniform distribution in the range $[-1,1]$ and $l^{t}$ is the average loudness at this timestamp. The fitness function is further improved if the generated random number is smaller than loudness. A new solution is obtained during the exploration process, and the parameters such as emission rates and loudness are updated. Mathematically, the parameter update is formulated as

$$
\begin{aligned}
& l_{i}^{t+1}=\rho l_{i}^{t}, \\
& r_{i}^{t+1}=r_{i}\left(1-e^{(-\alpha t)}\right),
\end{aligned}
$$

where $\rho$ is constant whose range is defined as $[0,1]$ and $\alpha$ is the positive constant. The bat's food-searching behavior is related to energy tracking to obtain the $P_{\max }$ point in the solar PV model.

3.4. Grey Wolf Optimization. GWO is a metaheuristic optimization algorithm that is derived based on the hunting nature of grey wolves. It is a type of swarm intelligence algorithm that efficiently solves nonlinear optimization issues. The structure of grey wolves includes an alpha $(\alpha)$ that is the leader of the group, beta $(\beta)$ that is the subordinates of $\alpha$, and the reaming delta $(\delta)$ and omega $(\omega)$ that are the third- and fourth-class supporting wolves. Alpha wolves are the leaders and provide the best fitness solution for the given optimization problem. The hunting steps of grey wolves include the following: (1) prey search, (2) encircling the prey, and (3) attacking the prey. GWO has high convergence speed and provides better accuracy than other optimization algorithms as it has a better balance between exploitation and exploration phases. To improve the performance of the optimization model, the search agents are limited, and the encircling behavior is formulated as

$$
\begin{aligned}
\vec{D} & =\left|\vec{C} \vec{x}_{p}(t)-\vec{x}_{s g}(t)\right|, \\
\vec{x}_{s g}(t+1) & =\vec{x}_{p}(t)-\vec{A} \cdot \vec{D},
\end{aligned}
$$

where $\vec{A}$ and $\vec{C}$ are the coefficients that balance the exploitation and exploration factors and are given as $\vec{A}=$ $\left(2 \vec{a} * \vec{r}_{1}\right)-(a)$ and $\vec{C}=2 \vec{r}_{2}$, in which the factors $\vec{r}_{1}$ and $\vec{r}_{2}$ are random numbers whose range is $[0,1]$. The range of coefficient (a) gradually decreased from 2 to 0 for every iteration, which indicates the wolves approach the prey. The position of best search agents is used to update the position of all agents for every iteration, and it is given as

$$
\begin{aligned}
\vec{D}_{\alpha} & =\left|\vec{c}_{1} \vec{x}_{\alpha}-\vec{x}_{s g}\right|, \\
\vec{D}_{\beta} & =\left|\vec{c}_{2} \vec{x}_{\beta}-\vec{x}_{s g}\right|, \\
\vec{x}_{1} & =\vec{x}_{\alpha}-\vec{A}_{1} * \vec{D}_{\alpha}, \\
\vec{x}_{2} & =\vec{x}_{\beta}-\vec{A}_{1} * \vec{D}_{\beta}, \\
\vec{x}_{s g}(t+1) & =\frac{\left(\vec{x}_{1}+\vec{x}_{2}\right)}{2} .
\end{aligned}
$$

The hunting process is stopped if the prey has stopped its movement and the search agents have finished the attacking process. The position update and attacking procedure of grey wolves are depicted in Figure 3.

The proposed optimization model is used to maximize the output power of PV array considering its $D$ as the decision variable. In the initialization process, the population is limited in the range of 0.1 to 0.9 of $D$, and it is expressed as

$$
d_{i}=\operatorname{rand}\left(n_{p}, 1\right)\left(d_{\max }-d_{\min }\right)+d_{\min },
$$

where $d_{i}$ is the $D$ and $n_{p}$ is the initial population, which refers to the number of PV systems.

The position of the prey is obtained by calculating the fitness function. In the proposed model, the values $d_{\alpha}$ and $d_{\beta}$ are considered the first- and second-best solutions with the highest PV power. To update the position of search agents based on the position of $d_{\alpha}$ and $d_{\beta}$, the population position and $D$ are updated, and they are given as

$$
\begin{aligned}
\vec{D}_{\alpha} & =\left|\vec{c}_{1} \vec{d}_{\alpha}-\vec{d}_{i}\right|, \\
\vec{D}_{\beta} & =\left|\vec{c}_{2} \vec{d}_{\beta}-\vec{d}_{i}\right|, \\
\vec{d}_{1} & =\vec{d}_{\alpha}-\vec{A}_{1} * \vec{D}_{\alpha}, \\
\vec{d}_{2} & =\vec{d}_{\beta}-\vec{A}_{1} * \vec{D}_{\beta}, \\
\vec{d}_{i}(t+1) & =\frac{\left(\vec{d}_{1}+\vec{d}_{2}\right)}{2} .
\end{aligned}
$$




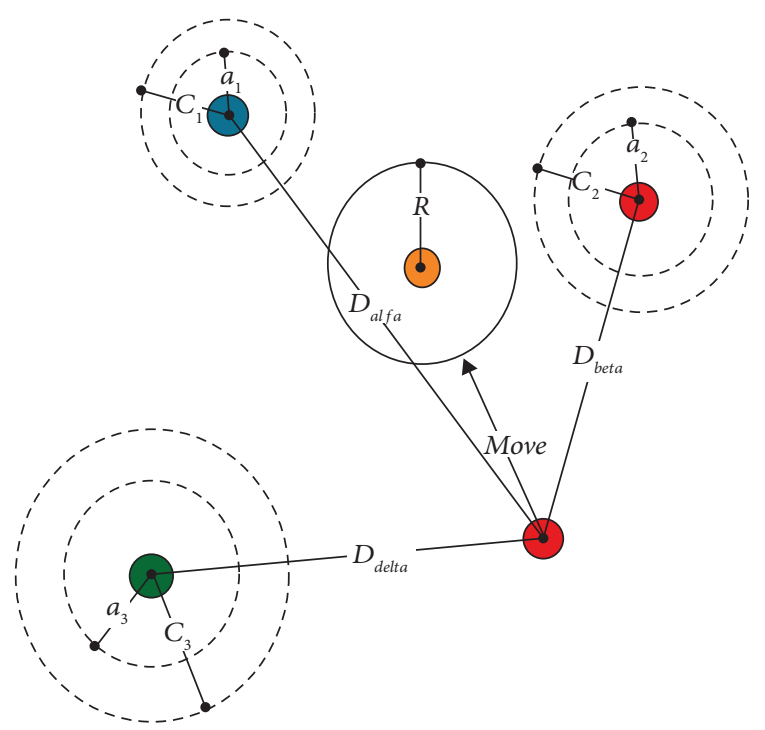

Figure 3: Position update and hunting of grey wolves.

The powers are calculated, and the process needs to be terminated when $P_{\max }$ is obtained. The maximum iteration and maximum output power are the termination criteria for the process, and they can be reinitialized if the power is reduced, and the process is given as

$$
\frac{\left|p_{p v}-p_{p v, l}\right|}{p_{p v, l}} \geq \Delta P,
$$

where $\Delta P$ represents the last operating point and $p_{p v, l}$ represents the power at the global $P_{\max }$ point. The process flow of GWO-based MPPT is given in Figure 4.

\section{Results and Discussion}

The proposed model performance is verified through a simulation designed in the MATLAB Simulink tool. The PV cell specifications are given in Table 1, and Figure 5 depicts the arrangement of the single-diode solar PV model. The performances are measured under different irradiance and temperature values, and the observations are discussed in this section.

The Simulink model for the proposed single-diode model is given in Figure 6. Initially, the parameters are extracted, and the performance of the single-diode PV model is analyzed under different irradiance and temperature conditions.

The P-V characteristics of the single-diode PV model are analyzed under different irradiance values in the range $[1000,800,600,400,200] \mathrm{W} / \mathrm{m}^{2}$, and the $25^{\circ} \mathrm{C}$ reference temperature is fixed for the analysis shown in Figure 7. It could be observed from the analysis that $P_{\max }$ is obtained for the irradiance value 1000, whereas for others, the power gets decreased gradually and irradiance of $200 \mathrm{~W} / \mathrm{m}^{2}$ exhibits the lowest power among all others.

The I-V characteristics of the single-diode PV model are depicted in Figure 8 for different irradiance values in the range $[1000,800,600,400,200] \mathrm{W} / \mathrm{m}^{2}$ with a reference temperature of $25^{\circ} \mathrm{C}$. The maximum current is obtained for $1000 \mathrm{~W} / \mathrm{m}^{2}$, and the lowest current is obtained for $200 \mathrm{~W} /$ $\mathrm{m}^{2}$.

In the next analysis, the irradiance is kept constant and the temperature is varied in the range $\left[10^{\circ} \mathrm{C}, 30^{\circ} \mathrm{C}, 60^{\circ} \mathrm{C}\right]$, and the $\mathrm{P}-\mathrm{V}$ characteristics are observed and depicted in Figure 9 . When the voltage increases, the power generation increases linearly, reaches the maximum for minimum temperature, and exhibits a lower power for a maximum temperature of $60^{\circ} \mathrm{C}$. This indicates the effect of temperature on power generation.

The I-V characteristics depicted in Figure 10 are observed by holding the irradiance at a constant value, and the temperature is varied in the range $\left[10^{\circ} \mathrm{C}, 30^{\circ} \mathrm{C}, 60^{\circ} \mathrm{C}\right]$. When the voltage increases, the power generation decreases and reaches a minimum value. However, the minimum temperature does not introduce much effect on the results, whereas the maximum temperature of $60^{\circ} \mathrm{C}$ reduces quickly than others, which indicates the effect of temperature on current characteristics.

Furthermore, to analyze and improve the performance of the PV model, optimization-based MPPT is introduced in the proposed work. Four optimization models are included for the analysis, and based on the performance, the best model is selected. Five PV arrays are connected in series, and a partial shading condition is considered for the analysis. The experimentation is performed under three cases for better validation, and the cases are given as follows:

Case 1: uniform irradiance of $1000 \mathrm{~W} / \mathrm{m}^{2}$ is applied in G3, G4, and G5, and nonuniform irradiance is applied in remaining panels $\mathrm{G} 1$ and G2

Case 2: uniform irradiance of $1000 \mathrm{~W} / \mathrm{m}^{2}$ is applied in G4 and G5, and nonuniform irradiance is applied in remaining panels G1, G2, and G3

Case 3: uniform irradiance of $1000 \mathrm{~W} / \mathrm{m}^{2}$ is applied in $\mathrm{G} 5$, and nonuniform irradiance is applied in remaining panels G1, G2, G3, and G4

For each case, five simulation tests are conducted and the performances are measured in terms of $P_{\max }$, MPPT power (MPPTP), and TE. The tracking efficiency (TE) is obtained based on the ratio between maximum power and MPPT power, and it is formulated as

$$
\eta=\frac{P_{\mathrm{MPPT}}}{P_{\max }} \times 100 .
$$

The optimized MPPT model for the proposed work is depicted in Figure 11. The Simulink model includes the PSObased MPPT model, and the same model is used for all the optimization by replacing respective optimization units for GA optimization, BAT optimization, and GWO in the design. The rest of the elements are similar for all the optimization models. The performance of the PSO-based MPPT model is analyzed for all three cases and listed in Tables 2-4 for cases $1-3$, respectively. It is observed from the analysis the PSObased MPPT process obtains an average TE of $96 \%$.

The performance of the GA-based MPPT model is analyzed for all three cases and listed in Tables 5-7, 


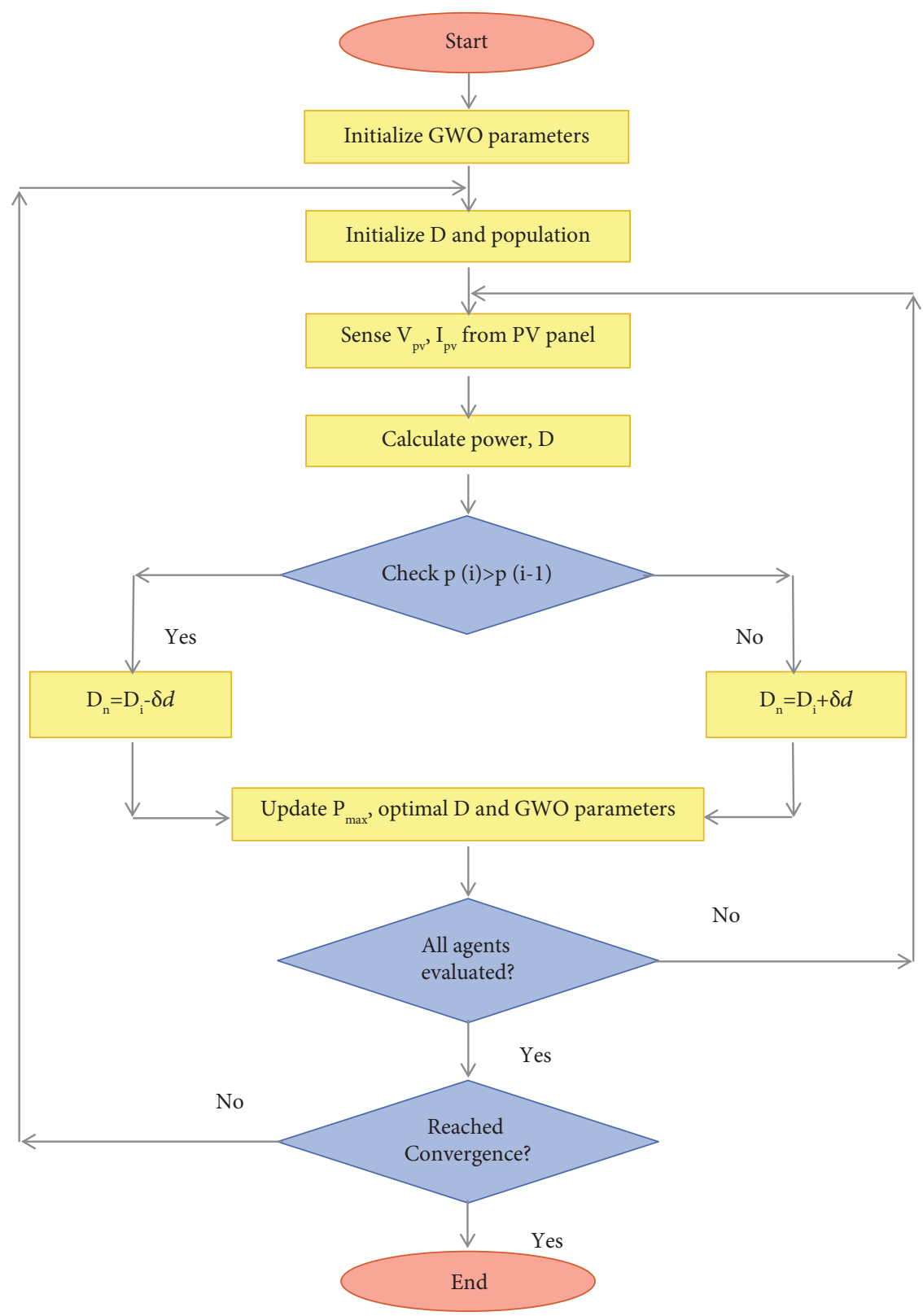

Figure 4: Process flow of GWO-based MPPT.

TABle 1: Solar PV cell specification.

\begin{tabular}{lcc}
\hline S. no. & Parameter & Range \\
\hline 1 & Input power & $260 \mathrm{~W}$ \\
2 & Short circuit current $\left(I_{s c}\right)$ & $8.67 \mathrm{~A}$ \\
3 & Open-circuit voltage $\left(V_{o c}\right)$ & $37.92 \mathrm{~V}$ \\
4 & Temperature coefficient of $I_{s c}$ & $0.06 \%$ per ${ }^{\circ} \mathrm{C}$ \\
5 & Temperature coefficient of $V_{o c}$ & $-0.33 \%$ per ${ }^{\circ} \mathrm{C}$ \\
6 & Reference temperature & $25^{\circ} \mathrm{C}$ \\
\hline
\end{tabular}

respectively. It is observed from the analysis the GA-based MPPT process obtains an average TE of $93 \%$, which is much less than that of the PSO-based MPPT model.

The performance of the BAT optimization-based MPPT model is analyzed for all three cases and listed in Tables 8-10, respectively. It is observed from the analysis the BAT optimization-based MPPT process obtains an average TE of $97 \%$, which is $4 \%$ higher than that of the GA-based MPPT model and $1 \%$ higher than that of the PSO-based MPPT model. 


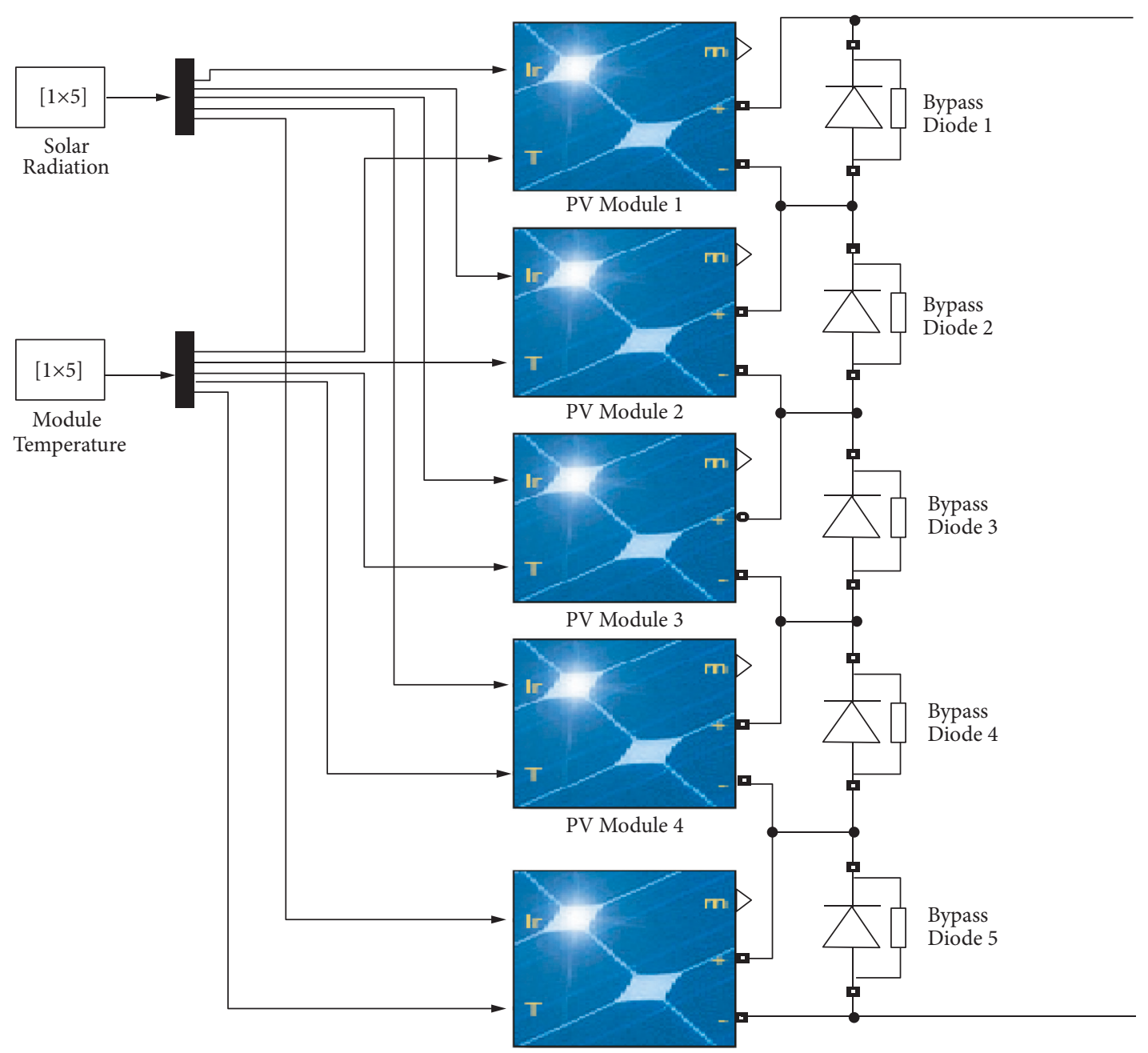

PV Module 5

Figure 5: Proposed single-diode PV array model.

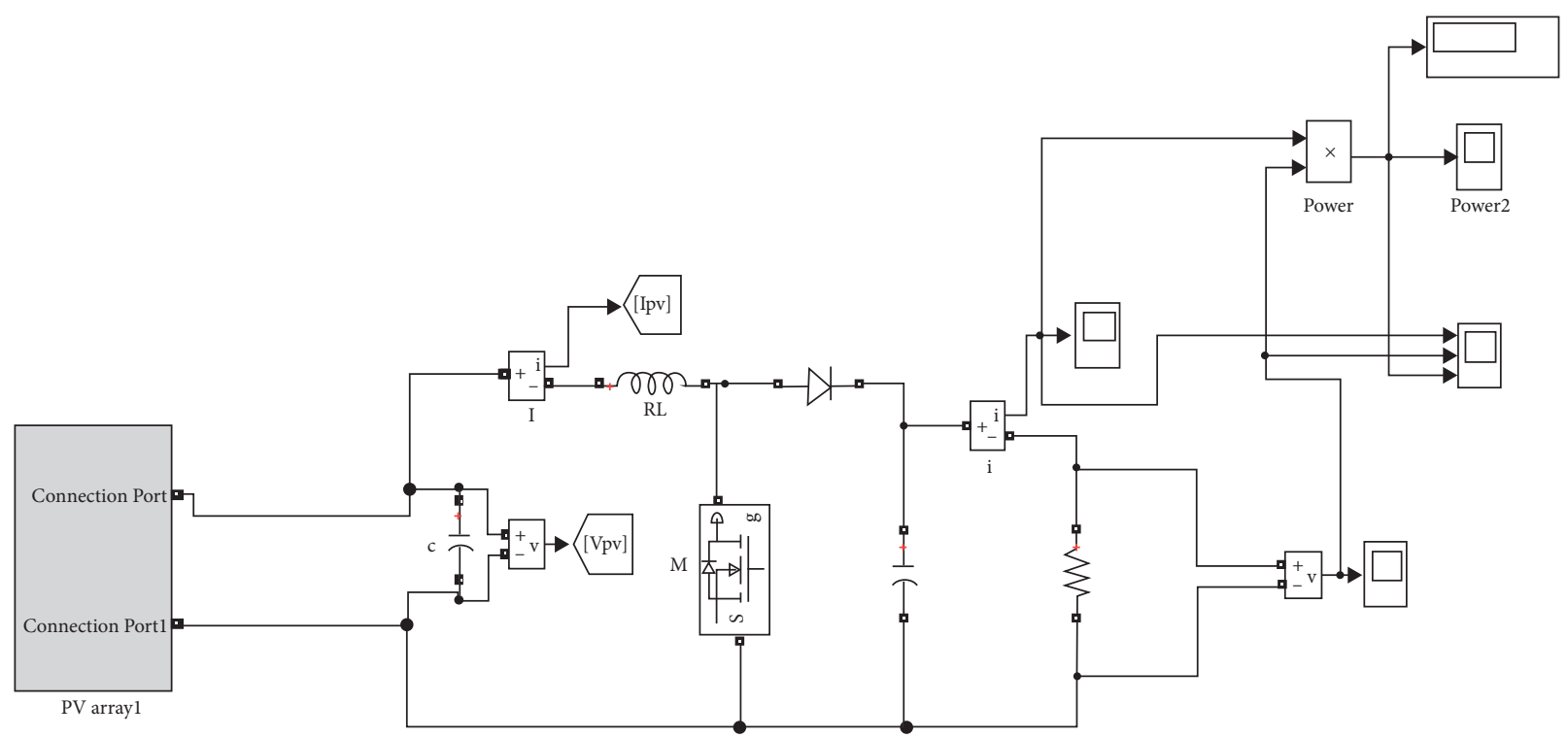

FIGURE 6: Simulink model of the proposed single-diode PV array. 


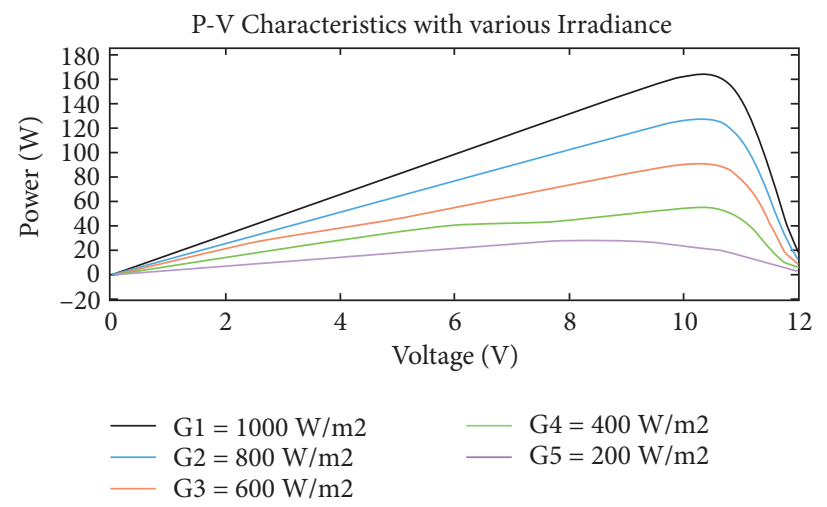

Figure 7: P-V characteristics under various irradiances in the range $[1000,800,600,400,200] \mathrm{W} / \mathrm{m}^{2}$.

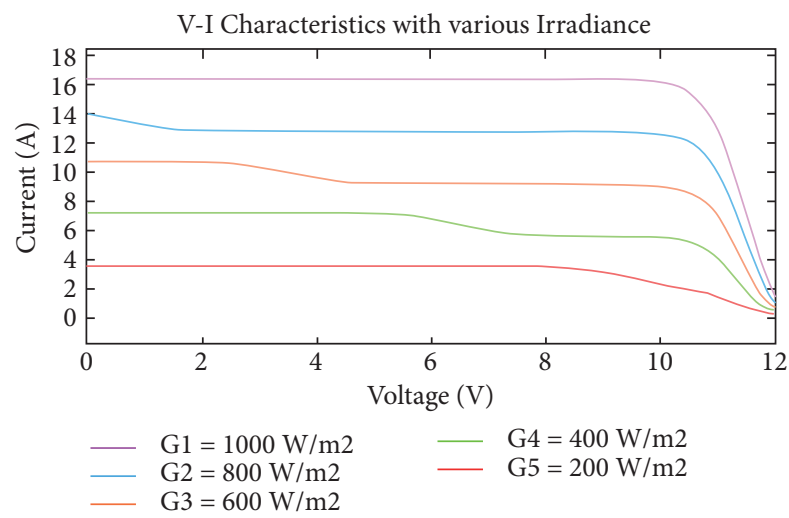

Figure 8: I-V characteristics under various irradiances in the range $[1000,800,600,400,200] \mathrm{W} / \mathrm{m}^{2}$.

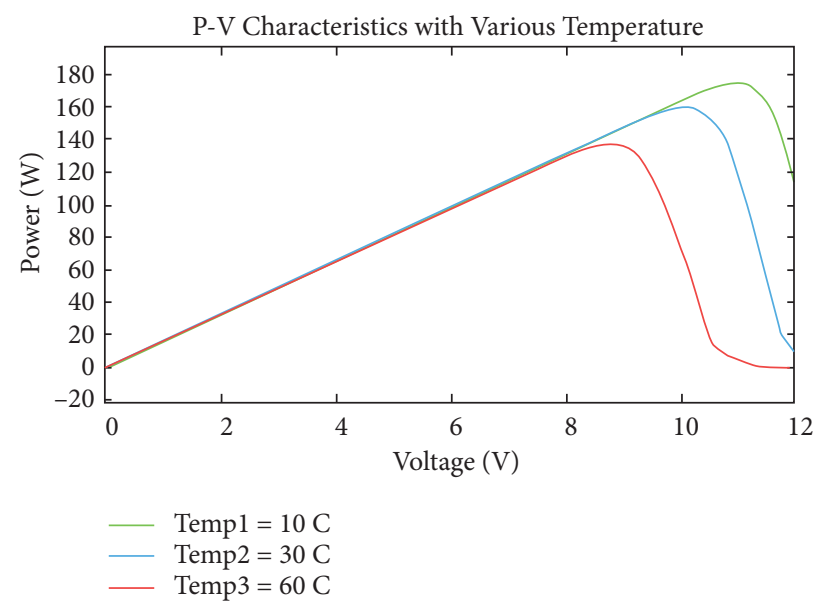

FIGURE 9: P-V characteristics at various temperatures.

The performance of the GWO-based MPPT model is analyzed for all three cases and listed in Tables 11-13, respectively. It is observed from the analysis the GWO-based MPPT process obtains an average TE of $98 \%$, which is $5 \%$ higher than that of the GA-based MPPT model, 2\% higher than that of the PSO-based MPPT model, and 1\% greater than that of the BAT optimization-based MPPT model.

The TE of all the optimization models is compared and depicted in Figures 12-14 for cases 1-3, respectively. It could be observed from the analysis the TE of the GWO model is higher than that of other optimization models in all the three cases. The fast convergence and accuracy of GWO have obtained maximum TE compared to those of other optimization models. For case 1, for all the five test conditions, the tracking efficiency obtained by GWO is above $98 \%$, whereas the tracking efficiency of BAT optimization obtains an average of $97 \%$ and PSO attains $96 \%$ tracking efficiency. The least performance is attained by the genetic algorithm, 


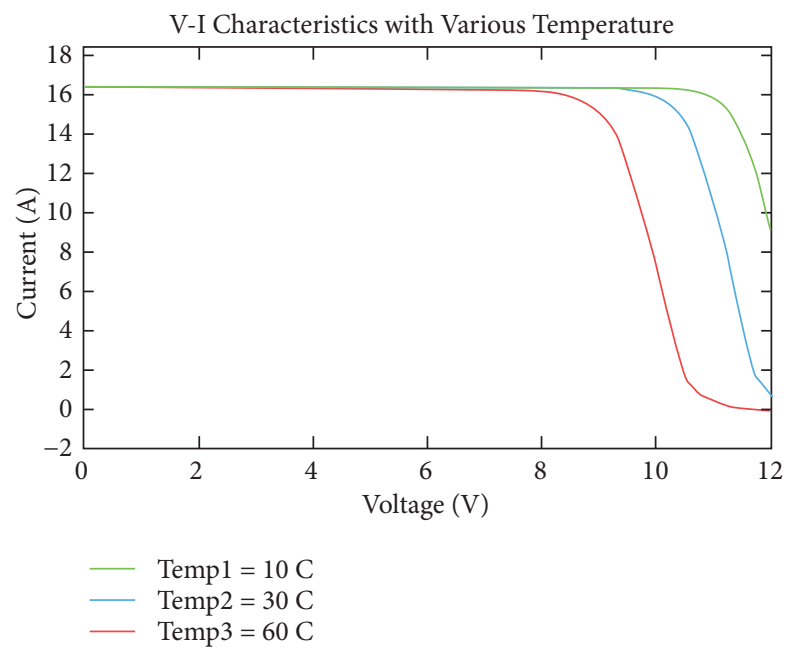

Figure 10: I-V characteristics at various temperatures.

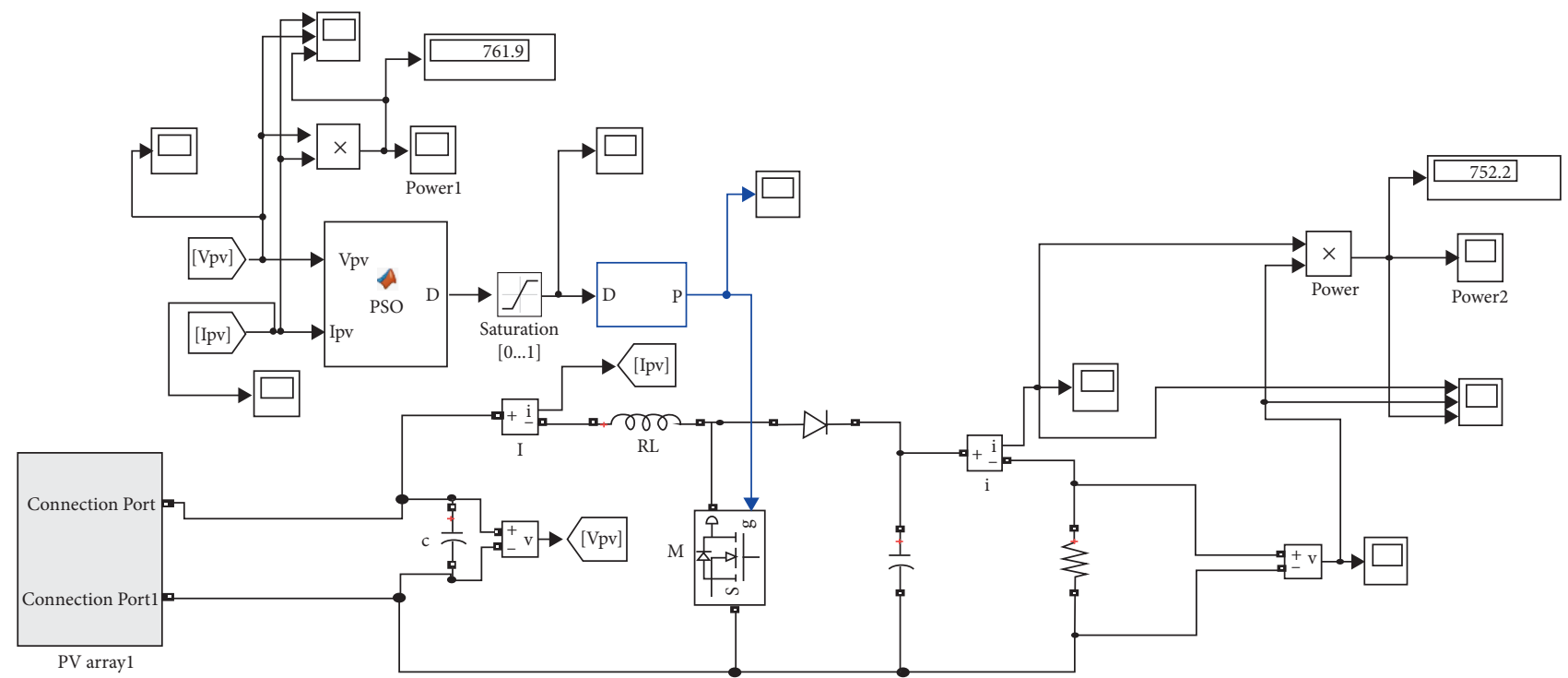

FIGURE 11: Simulink design-optimized MPPT model.

TABLE 2: PSO-based MPPT performance for case 1.

\begin{tabular}{lcccccccc}
\hline Test & G1 & G2 & G3 & G4 & G5 & $P_{\max }$ & MPPTP & TE (\%) \\
\hline 1 & 900 & 950 & 1000 & 1000 & 1000 & 974.1 & 936.7 & 879.5 \\
2 & 810 & 860 & 1000 & 1000 & 1000 & 910.2 & 96.63 \\
3 & 720 & 770 & 1000 & 1000 & 1000 & 857.7 & 826.1 & 96.32 \\
4 & 610 & 680 & 1000 & 1000 & 1000 & 712.6 & 689.9 & 96.81 \\
5 & 550 & 580 & 1000 & 1000 & 1000 & 621.1 & 596.3 & 96.01 \\
\hline
\end{tabular}

TABLE 3: PSO-based MPPT performance for case 2.

\begin{tabular}{llllllllr}
\hline Test & G1 & G2 & G3 & G4 & G5 & $P_{\max }$ & MPPTP & TE (\%) \\
\hline 1 & 910 & 940 & 970 & 1000 & 1000 & 937.3 & 908.2 & 944.6 \\
2 & 800 & 850 & 890 & 1000 & 1000 & 876.1 & 96.90 \\
3 & 710 & 750 & 780 & 1000 & 1000 & 756.7 & 731.2 \\
4 & 620 & 660 & 690 & 1000 & 1000 & 670.6 & 643.7 & 96.63 \\
5 & 500 & 550 & 590 & 1000 & 1000 & 579.5 & 559.3 & 95.99 \\
\hline
\end{tabular}


TABLE 4: PSO-based MPPT performance for case 3.

\begin{tabular}{lcccccccc}
\hline Test & G1 & G2 & G3 & G4 & G5 & $P_{\max }$ & MPPTP & TE (\%) \\
\hline 1 & 900 & 930 & 960 & 890 & 1000 & 934.5 & 902.3 & 96.55 \\
2 & 800 & 840 & 870 & 780 & 1000 & 856.7 & 824.4 & 96.23 \\
3 & 700 & 730 & 760 & 670 & 1000 & 736.2 & 704.3 \\
4 & 600 & 670 & 640 & 570 & 1000 & 646.9 & 619.8 \\
5 & 500 & 540 & 580 & 490 & 1000 & 549.7 & 527.2 & 95.81 \\
\hline
\end{tabular}

TABLE 5: GA-based MPPT performance for case 1.

\begin{tabular}{lcccccccc}
\hline Test & G1 & G2 & G3 & G4 & G5 & $P_{\max }$ & MPPTP & TE (\%) \\
\hline 1 & 900 & 950 & 1000 & 1000 & 1000 & 971.3 & 909.4 \\
2 & 810 & 860 & 1000 & 1000 & 1000 & 912.4 & 857.3 & 93.63 \\
3 & 720 & 770 & 1000 & 1000 & 1000 & 862.1 & 798.1 \\
4 & 610 & 680 & 1000 & 1000 & 1000 & 710.8 & 663.7 \\
5 & 550 & 580 & 1000 & 1000 & 1000 & 598.8 & 552.4 & 93.37 \\
\hline
\end{tabular}

TAвLE 6: GA-based MPPT performance for case 2.

\begin{tabular}{llllllllc}
\hline Test & G1 & G2 & G3 & G4 & G5 & $P_{\max }$ & MPPTP & TE (\%) \\
\hline 1 & 910 & 940 & 970 & 1000 & 1000 & 942.1 & 876.8 \\
2 & 800 & 850 & 890 & 1000 & 1000 & 883.7 & 827.4 & 93.07 \\
3 & 710 & 750 & 780 & 1000 & 1000 & 763.5 & 712.3 & 93.63 \\
4 & 620 & 660 & 690 & 1000 & 1000 & 664.9 & 623.7 & 93.80 \\
5 & 500 & 550 & 590 & 1000 & 1000 & 569.3 & 527.8 & 92.71 \\
\hline
\end{tabular}

TABLE 7: GA-based MPPT performance for case 3.

\begin{tabular}{|c|c|c|c|c|c|c|c|c|}
\hline Test & G1 & G2 & G3 & G4 & G5 & $P_{\max }$ & МРPТР & TE (\%) \\
\hline 1 & 900 & 930 & 960 & 890 & 1000 & 941.8 & 880.2 & 93.46 \\
\hline 2 & 800 & 840 & 870 & 780 & 1000 & 864.6 & 812.4 & 93.96 \\
\hline 3 & 700 & 730 & 760 & 670 & 1000 & 743.1 & 694.7 & 93.49 \\
\hline 4 & 600 & 670 & 640 & 570 & 1000 & 652.7 & 607.9 & 93.14 \\
\hline 5 & 500 & 540 & 580 & 490 & 1000 & 543.2 & 504.2 & 92.82 \\
\hline
\end{tabular}

TABLE 8: BAT optimization-based MPPT performance for case 1.

\begin{tabular}{lcccccccc}
\hline Test & G1 & G2 & G3 & G4 & G5 & $P_{\max }$ & MPPTP & TE (\%) \\
\hline 1 & 900 & 950 & 1000 & 1000 & 1000 & 963.2 & 937.2 & 97.30 \\
2 & 810 & 860 & 1000 & 1000 & 1000 & 907.8 & 83.2 & 97.29 \\
3 & 720 & 770 & 1000 & 1000 & 1000 & 859.9 & 837.1 & 97.35 \\
4 & 610 & 680 & 1000 & 1000 & 1000 & 720.1 & 702.4 & 97.54 \\
5 & 550 & 580 & 1000 & 1000 & 1000 & 610.2 & 591.2 & 96.89 \\
\hline
\end{tabular}

TABLE 9: BAT optimization-based MPPT performance for case 2.

\begin{tabular}{llllllllc}
\hline Test & G1 & G2 & G3 & G4 & G5 & $P_{\max }$ & MPPTP & TE (\%) \\
\hline 1 & 910 & 940 & 970 & 1000 & 1000 & 937.8 & 916.7 & 973.5 \\
2 & 800 & 850 & 890 & 1000 & 1000 & 894.8 & 97.62 \\
3 & 710 & 750 & 780 & 1000 & 1000 & 780.9 & 764.5 & 97.90 \\
4 & 620 & 660 & 690 & 1000 & 1000 & 678.1 & 659.8 & 97.30 \\
5 & 500 & 550 & 590 & 1000 & 1000 & 579.4 & 563.8 & 97.31 \\
\hline
\end{tabular}

which attains 93\% tracking efficiency. For case 2, the tracking efficiency of GA, PSO, BAT optimization, and GWO is $93.3 \%, 96.486 \%, 97.576 \%$, and $98.164 \%$, respectively. For case 3 , the tracking efficiency of GA, PSO, BAT optimization, and GWO is $93.374 \%, 96.034 \%, 96.974 \%$, and $98.284 \%$, respectively. The average tracking efficiency considering all the three cases attained by the optimization models is $93.3 \%$ for GA, $96.3 \%$ for PSO, $97.3 \%$ for BAT 
TABLE 10: BAT optimization-based MPPT performance for case 3.

\begin{tabular}{lcccccccc}
\hline Test & G1 & G2 & G3 & G4 & G5 & $P_{\max }$ & MPPTP & TE (\%) \\
\hline 1 & 900 & 930 & 960 & 890 & 1000 & 936.7 & 910.4 & 97.19 \\
2 & 800 & 840 & 870 & 780 & 1000 & 875.2 & 847.9 & 96.88 \\
3 & 700 & 730 & 760 & 670 & 1000 & 751.1 & 725.7 & 96.62 \\
4 & 600 & 670 & 640 & 570 & 1000 & 674.9 & 654.9 & 97.04 \\
5 & 500 & 540 & 580 & 490 & 1000 & 549.8 & 534.1 & 97.14 \\
\hline
\end{tabular}

TABLE 11: GWO-based MPPT performance for case 1.

\begin{tabular}{lcccccccc}
\hline Test & G1 & G2 & G3 & G4 & G5 & $P_{\max }$ & MPPTP & TE (\%) \\
\hline 1 & 900 & 950 & 1000 & 1000 & 1000 & 957.8 & 942.7 & 98.42 \\
2 & 810 & 860 & 1000 & 1000 & 1000 & 910.7 & 996.2 \\
3 & 720 & 770 & 1000 & 1000 & 1000 & 849.3 & 829.4 & 97.41 \\
4 & 610 & 680 & 1000 & 1000 & 1000 & 728.8 & 716.1 \\
5 & 550 & 580 & 1000 & 1000 & 1000 & 623.4 & 612.8 & 98.26 \\
\hline
\end{tabular}

TABLE 12: GWO-based MPPT performance for case 2.

\begin{tabular}{llllllllr}
\hline Test & G1 & G2 & G3 & G4 & G5 & $P_{\max }$ & MPPTP & TE (\%) \\
\hline 1 & 910 & 940 & 970 & 1000 & 1000 & 920.4 & 907.8 & 98.63 \\
2 & 800 & 850 & 890 & 1000 & 1000 & 884.7 & 98.1 \\
3 & 710 & 750 & 780 & 1000 & 1000 & 772.9 & 759.5 & 98.27 \\
4 & 620 & 660 & 690 & 1000 & 1000 & 684.5 & 669.9 & 97.87 \\
5 & 500 & 550 & 590 & 1000 & 1000 & 571.2 & 560 & 98.04 \\
\hline
\end{tabular}

TABLE 13: GWO-based MPPT performance for case 3.

\begin{tabular}{lcccccccc}
\hline Test & G1 & G2 & G3 & G4 & G5 & $P_{\max }$ & MPPTP & TE (\%) \\
\hline 1 & 900 & 930 & 960 & 890 & 1000 & 927.9 & 916.2 & 98.74 \\
2 & 800 & 840 & 870 & 780 & 1000 & 873.8 & 957.3 & 98.11 \\
3 & 700 & 730 & 760 & 670 & 1000 & 763.3 & 951.7 & 98.48 \\
4 & 600 & 670 & 640 & 570 & 1000 & 680.1 & 668.4 \\
5 & 500 & 540 & 580 & 490 & 1000 & 551.8 & 539.7 & 97.28 \\
\hline
\end{tabular}

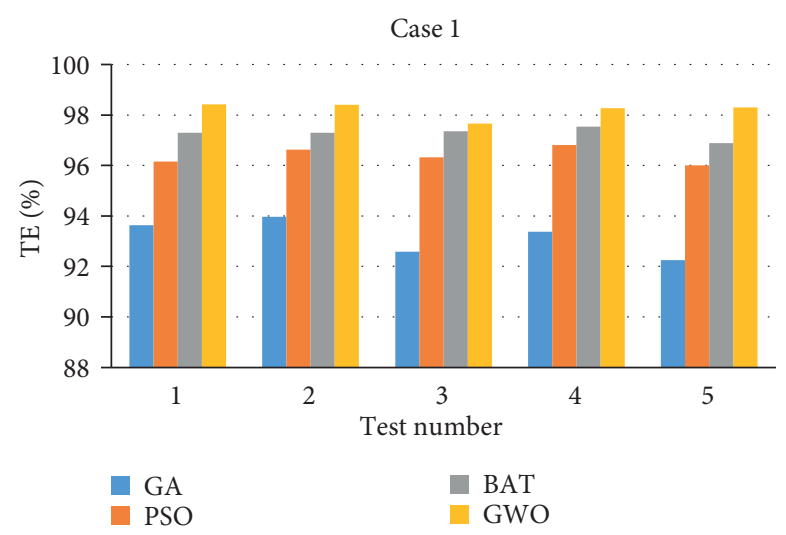

FIgURE 12: TE comparisons for case 1.

optimization, and $98.2 \%$ for GWO. It is observed that maximum performance is attained by the GWO model, which increases the performance of PV systems.

From the analysis, it could be observed that GWO exhibits maximum TE and power in all the cases compared to other optimization algorithms. The performance of the single-diode PV model can be improved with the GWObased MPPT strategy. Compared to other optimization models, GWO has a much better convergence rate and provides maximum power tracking, which increases the total power, whereas the convergence rate of PSO is better than that of GA but less than that of GWO, and in the case of 


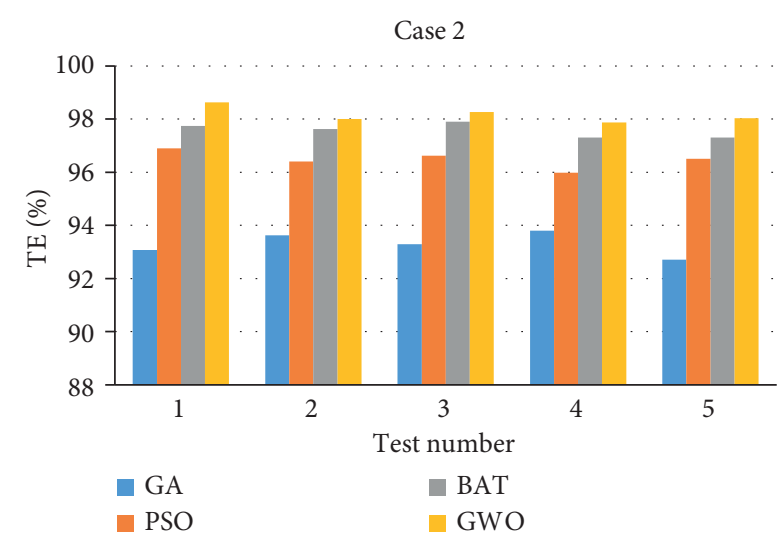

FIgURE 13: TE comparisons for case 2.

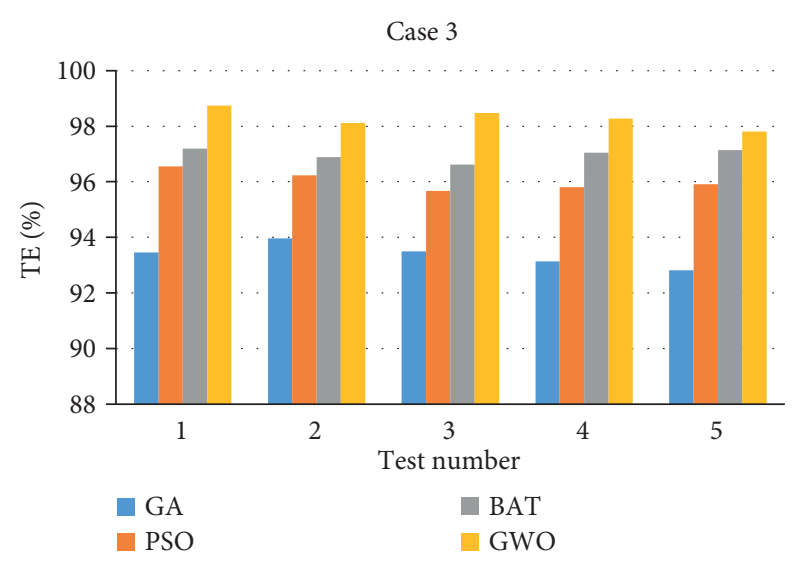

FIgURE 14: TE comparisons for case 3.

BAT optimization, the convergence rate is better than that of PSO and GA but less than that of the GWO model. This indicates that, with minimum time, the GWO model attains maximum performance so that it can be selected as the best optimization model among other optimization algorithms.

\section{Conclusion}

This research work presents an analysis of a single-diode PV model and MPPT using optimization techniques to improve the performance of solar PV systems. The parameters of the single-diode model are derived, and the I-V and P-V characteristics are analyzed under different conditions. Irradiance and temperature are varied to measure the characteristics. Furthermore, four optimization models such as PSO, GA, BAT optimization, and GWO are introduced to obtain MPPT of the proposed system. The performance is analyzed under three different cases by varying the irradiance levels. Among all four optimization techniques, the GWO-based MPPT model attains approximately 98\% TE, which is much better than that of other optimization techniques. Furthermore, this research work can be improved by integrating Internet of things models for fault detection so that the factors that affect the TE can be identified and replaced immediately.

\section{Symbols}

\begin{tabular}{|c|c|}
\hline$V_{d}:$ & Potential difference \\
\hline$I_{o}:$ & Reverse saturation current \\
\hline$V_{t}$ : & Thermal voltage \\
\hline$N_{s}$ : & Series-connected cells \\
\hline$k:$ & Boltzmann constant $\left(1.380650 \times 10^{-23} \mathrm{~J} / \mathrm{K}\right)$ \\
\hline$q:$ & Electron charge $\left(1.602176 \times 10^{-19} \mathrm{C}\right)$ \\
\hline$T:$ & Temperature \\
\hline$I_{p g}:$ & The current generated by photovoltaic effect \\
\hline$I_{d}:$ & Diode current \\
\hline$I_{s}:$ & Diode saturation current \\
\hline$R_{s}:$ & Series resistance \\
\hline$R_{s h}:$ & Shunt resistance \\
\hline$\Delta I_{l}(i):$ & Change in current point \\
\hline$\Delta V_{l}(i)$ & Change in voltage point \\
\hline$V_{o c}:$ & Open-circuit voltage \\
\hline$V_{p}:$ & Maximum power point voltage \\
\hline$x_{i i}^{t}:$ & Position vector of the $i^{\text {th }}$ particle at iteration $\mathrm{t}$ \\
\hline$x_{i j}^{t+1}:$ & Position vector of the $i^{\text {th }}$ particle at iteration $t+1$ \\
\hline$c_{1}$ and $c_{2}$ : & Coefficients \\
\hline$\vec{r}_{2}$ and & $\begin{array}{l}\text { Random numbers distributed uniformly in the } \\
\text { range }[0,1]\end{array}$ \\
\hline$P_{\mathrm{pv}}^{2}:$ & Power of the photovoltaic system \\
\hline$V:$ & Output voltage \\
\hline$C(k):$ & Next-generation solution \\
\hline$V_{i}:$ & Random bat's velocity \\
\hline$X_{i}:$ & The position of bats \\
\hline$L_{i}:$ & The loudness of bats \\
\hline$F_{i}$ : & Randomly assigned frequency \\
\hline$\varphi:$ & Random vector for uniform distribution \\
\hline$\rho:$ & Constant \\
\hline$\alpha:$ & Positive constant \\
\hline$\vec{A}$ and $\vec{C}$ : & Coefficients in grey wolf optimization \\
\hline$\beta:$ & Beta-subordinates of $\alpha$ \\
\hline$\delta$ and $\omega:$ & $\begin{array}{l}\text { Delta and omega-third- and fourth-class } \\
\text { supporting wolves }\end{array}$ \\
\hline$D_{i}:$ & Duty cycle \\
\hline$N_{p}:$ & Initial population \\
\hline$\Delta P$ & Last operating point. \\
\hline
\end{tabular}

\section{Data Availability}

The reference articles data used to support the findings of this study are included within this article.

\section{Additional Points}

Highlights. (1) A mathematical model for a single-diode PV system and four optimization approaches for MPPT under different environmental conditions are presented in this research work. (2) The simulation results demonstrate that the grey wolf optimization model achieves a maximum power tracking efficiency of $98 \%$, which is better than that of other competing optimization techniques such as BAT optimization (97\%), PSO (96\%), and GA (93\%). 


\section{Conflicts of Interest}

The authors declare that they have no conflicts of interest.

\section{References}

[1] S. Siah Chehreh Ghadikolaei, "An enviroeconomic review of the solar PV cells cooling technology effect on the $\mathrm{CO}_{2}$ emission reduction," Solar Energy, vol. 216, pp. 468-492, 2021.

[2] E. Hache and A. Palle, "Renewable energy source integration into power networks, research trends and policy implications: a bibliometric and research actors survey analysis," Energy Policy, vol. 124, pp. 23-35, 2019.

[3] S. Talari, M. Shafie-khah, G. J. Osório, J. Aghaei, J. P. S. Catalão, and S. Catalão, "Stochastic modelling of renewable energy sources from operators' point-of-view: a survey," Renewable and Sustainable Energy Reviews, vol. 81, no. 2, pp. 1953-1965, 2018.

[4] G. Chitrakala, N. Stalin, and V. Mohan, "Normally bypassed cascaded sources multilevel inverter with RGA optimization for reduced output distortion and formulaic passive filter design," Journal of Circuits, Systems, and Computers, vol. 29, no. 2, Article ID 2050019, 2019.

[5] G. Chitrakala, N. Stalin, and V. Mohan, "A segmented ladderstructured multilevel inverter for switch count remission and dual-mode savvy," Journal of Circuits, Systems, and Computers, vol. 27, no. 14, Article ID 1850223, 2018.

[6] V. Mohan, G. Chitrakala, and N. Stalin, "A low frequency PWM based multilevel DC-link inverter with cascaded sources," Asian Journal of Research in Social Sciences and Humanities, vol. 7, no. 1, pp. 686-697, 2017.

[7] M. Vijayakumar and S. M. Ramesh, "Component count reduced, filter less H-bridge multilevel inverter with series and parallel connected switches," Journal of Circuits, Systems, and Computers, vol. 30, no. 3, p. 2150052, 2019.

[8] N. Shaukat, S. M. Ali, C. A. Mehmood et al., "A survey on consumers empowerment, communication technologies, and renewable generation penetration within smart grid," Renewable and Sustainable Energy Reviews, vol. 81, no. 1, pp. 1453-1475, 2018.

[9] L. V. Suresh Kumar and G. V. Nagesh Kumar, "Power conversion in renewable energy systems: a review advances in wind and PV system," International Journal of Energy Research, vol. 41, no. 2, 2016.

[10] B. P. Singh, S. K. Goyal, and P. Kumar, "Solar PV cell materials and technologies: analyzing the recent developments," $M a$ terials Today Proceedings, vol. 43, no. 5, pp. 2843-2849, 2021.

[11] V. Mohan, J. Raja, and S. Jeevanathan, "A random PWM scheme based on coalescing the pseudorandom triangular carrier and the randomized pulse position for voltage source inverters," Programmable Device Circuits and Systems, vol. 4, no. 11, 2012.

[12] N. B. Shankar and V. Mohan, "A novel invariable carrier frequency PWM scheme for balancing switching transitions in multi level inverter," International Journal of Engineering \& Technology Research, vol. 3, no. 1, pp. 1-7, 2015.

[13] R. Satpathy and V. Pamuru, "Manufacturing of crystalline silicon solar PV modules," Solar PV Power, pp. 135-241, 2020.

[14] P. J. S. Babu, T. S. Padmanabhan, M. I. Ahamed, and A. Sivaranjani, "Studies on copper indium selenide/zinc sulphide semiconductor quantum dots for solar cell applications," Chalcogenide Letters, vol. 18, no. 11, pp. 701-715, 2021.
[15] A. Mohanty, P. K. Ray, M. Viswavandya, S. Mohanty, and P. P. Mohanty, "Experimental analysis of a standalone solar photo voltaic cell for improved power quality," Optik, vol. 171, pp. 876-885, 2018.

[16] M. Akhsassi, A. El Fathi, N. Erraissi et al., "Experimental investigation and modeling of the thermal behavior of a solar PV module," Solar Energy Materials and Solar Cells, vol. 180, pp. 271-279, 2018.

[17] P. Pal, V. Mukherjee, P. Kumar, and M. E. Makhatha, "Prefeasibility analysis and performance assessment of solar photovoltaic (PV) modules for the application of renewable power generation," Materials Today Proceedings, vol. 39, no. 4, pp. 1813-1819, 2021.

[18] M. P. Almeida, M. Muñoz, I. de la Parra, and O. Perpiñán, "Comparative study of PV power forecast using parametric and nonparametric PV models," Solar Energy, vol. 155, pp. 854-866, 2017.

[19] M. B. H. Rhouma, A. Gastli, L. Ben Brahim, F. Touati, and M. Benammar, "A simple method for extracting the parameters of the PV cell single-diode model," Renewable Energy, vol. 113, pp. 885-894, 2017.

[20] M. C. D Piazza, M. Luna, G. Petrone, and G. Spagnuolo, "Translation of the single-diode PV model parameters identified by using explicit formulas," IEEE Journal of Photovoltaics, vol. 7, no. 4, pp. 1009-1016, 2017.

[21] L. E. Mathew and A. Panchal, "A complete numerical investigation on implicit and explicit PV single-diode-models using I- and V-approaches," IEEE Journal of Photovoltaics, vol. 11, no. 3, pp. 827-837, 2021.

[22] F. J. Toledo, J. M. Blanes, and V. Galiano, “Two-step linear least-squares method for photovoltaic single-diode model parameters extraction," IEEE Transactions on Industrial Electronics, vol. 65, no. 8, pp. 6301-6308, 2018.

[23] A. Abbassi, R. Gammoudi, M. Ali Dami, O. Hasnaoui, and M. Jemli, "An improved single-diode model parameters extraction at different operating conditions with a view to modeling a photovoltaic generator: a comparative study," Solar Energy, vol. 155, pp. 478-489, 2017.

[24] C. Zhang, Y. Zhang, J. Su, T. Gu, and M. Yang, "Modeling and prediction of PV module performance under different operating conditions based on power-law I-V model," IEEE Journal of Photovoltaics, vol. 10, no. 6, pp. 1816-1827, 2020.

[25] H. K. Mehta, H. Warke, K. Kukadiya, and A. K. Panchal, "Accurate expressions for single-diode-model solar cell parameterization," IEEE Journal of Photovoltaics, vol. 9, no. 3, pp. 803-810, 2019.

[26] F. Bradaschia, M. C. Cavalcanti, A. J. do Nascimento, E. A. da Silva, and G. M. de Souza Azevedo, "Parameter identification for PV modules based on an environment-dependent doublediode model," IEEE Journal of Photovoltaics, vol. 9, no. 5, pp. 1388-1397, 2019.

[27] P. Malik, M. A. El-Dabah, R. A. El-Sehiemy, M. Becherif, and M. A. Ebrahim, "Parameter estimation of triple diode photovoltaic model using an artificial ecosystem based optimizer," International Transactions on Electrical Energy Systems, pp. 1-20, 2021.

[28] A. A. Cárdenas, M. Carrasco, F. Mancilla-David, A. Street, and R. Cárdenas, "Experimental parameter extraction in the single-diode photovoltaic model via a reduced-space search," IEEE Transactions on Industrial Electronics, vol. 64, no. 2, pp. 1468-1476, 2017.

[29] E. Moshksar and T. Ghanbari, "Adaptive estimation approach for parameter identification of photovoltaic modules," IEEE Journal of Photovoltaics, vol. 7, no. 2, pp. 614-623, 2017. 
[30] C. F. Abe, J. B. Dias, G. Notton, and P. Poggi, "Computing solar irradiance and average temperature of photovoltaic modules from the maximum power point coordinates," IEEE Journal of Photovoltaics, vol. 10, no. 2, pp. 655-663, 2020.

[31] Y. Mahmoud and W. Xiao, "Evaluation of shunt model for simulating photovoltaic modules," IEEE Journal of Photovoltaics, vol. 8 , no. 6 , pp. 1818-1823, 2018.

[32] C. W. Hansen and B. H. King, "Determining series resistance for equivalent circuit models of a PV module," IEEE Journal of Photovoltaics, vol. 9, no. 2, pp. 538-543, 2019.

[33] Y. Hishikawa, T. Takenouchi, M. Higa, K. Yamagoe, H. Ohshima, and M. Yoshita, "Translation of solar cell performance for irradiance and temperature from a single I-V curve without advance information of translation parameters," IEEE Journal of Photovoltaics, vol. 9, no. 5, pp. 1195-1201, 2019.

[34] A. K. Panchal, "I-V data operated high-quality photovoltaic solution through per-unit single-diode model," IEEE Journal of Photovoltaics, vol. 10, no. 4, pp. 1175-1184, 2020.

[35] X. Ma, W.-H. Huang, E. Schnabel et al., "Data-driven I-V feature extraction for photovoltaic modules," IEEE Journal of Photovoltaics, vol. 9, no. 5, pp. 1405-1412, 2019.

[36] C. F. Abe, J. B. Dias, P. Poggi, and B. Pillot, "Combining identification and translation methods of the single-diode model to compute the average temperature of photovoltaic modules from the open-circuit voltage," IEEE Journal of Photovoltaics, vol. 9, no. 5, pp. 1398-1404, 2019.

[37] M. Hejri and H. Mokhtari, "On the comprehensive parametrization of the photovoltaic (PV) cells and modules," IEEE Journal of Photovoltaics, vol. 7, no. 1, pp. 250-258, 2017.

[38] R. Babu Bollipo, M. Suresh, and P. Kumar Bonthagorla, "Hybrid, optimal, intelligent and classical PV MPPT techniques: a review," CSEE Journal of Power and Energy Systems, vol. 7, no. 1, pp. 9-33, 2021.

[39] A. Ali, K. Almutairi, S. Padmanaban et al., "Investigation of MPPT techniques under uniform and non-uniform solar irradiation condition-a retrospection," IEEE Access, vol. 8, pp. 127368-127392, 2020.

[40] X. Antony and A. M. Bazzi, "Model-based maximum power curves of solar photovoltaic panels under partial shading conditions," IEEE Journal of Photovoltaics, vol. 8, no. 1, pp. 233-238, 2018.

[41] N. Rajasekar, M. Vysakh, H. V. Thakur et al., "Application of modified particle swarm optimization for maximum power point tracking under partial shading condition," Energy Procedia, vol. 61, pp. 2633-2639, 2014.

[42] K. Sangeetha, T. Sudhakar Babu, and N. Rajasekar, "Fireworks algorithm-based maximum power point tracking for uniform irradiation as well as under partial shading condition," in Artificial Intelligence and Evolutionary Computations in Engineering Systems, pp. 79-88, Springer, Berlin, Germany, 2016.

[43] M. Jedari Zare Zadeh and S. H. Fathi, "A new approach for photovoltaic arrays modeling and maximum power point estimation in real operating conditions," IEEE Transactions on Industrial Electronics, vol. 64, no. 12, pp. 9334-9343, 2017.

[44] K. Yan, Y. Du, and Z. Ren, "MPPT perturbation optimization of photovoltaic power systems based on solar irradiance data classification," IEEE Transactions on Sustainable Energy, vol. 10, no. 2, pp. 514-521, 2019.

[45] N. Priyadarshi, S. Padmanaban, J. B. Holm-Nielsen, F. Blaabjerg, and M. S. Bhaskar, "An experimental estimation of hybrid ANFIS-PSO-based MPPT for PV grid integration under fluctuating sun irradiance," IEEE Systems Journal, vol. 14, no. 1, pp. 1218-1229, 2020.
[46] H. Rezk, M. Aly, M. Al-Dhaifallah, and M. Shoyama, "Design and hardware implementation of new adaptive fuzzy logicbased MPPT control method for photovoltaic applications," IEEE Access, vol. 7, pp. 106427-106438, 2019.

[47] H. Li, D. Yang, W. Su, J. Lü, and X. Yu, "An overall distribution particle swarm optimization MPPT algorithm for photovoltaic system under partial shading," IEEE Transactions on Industrial Electronics, vol. 66, no. 1, pp. 265-275, 2019.

[48] A.-w. Ibrahim, M. B. Shafik, M. Ding et al., "PV maximum power-point tracking using modified particle swarm optimization under partial shading conditions," Chinese Journal of Electrical Engineering, vol. 6, no. 4, pp. 106-121, 2020.

[49] A. Ibnelouad, A. El Kari, A. Hassan, and M. Mjahed, "Improved cooperative artificial neural network-particle swarm optimization approach for solar photovoltaic systems using maximum power point tracking," International Transactions on Electrical Energy Systems, vol. 30, no. 8, pp. 1-14, 2020.

[50] S. Obukhov, A. Ibrahim, A. A. Zaki Diab, A. S. Al-Sumaiti, and R. Aboelsaud, "Optimal performance of dynamic particle swarm optimization based maximum power trackers for stand-alone PV system under partial shading conditions," IEEE Access, vol. 8, pp. 20770-20785, 2020.

[51] J. Prasanth Ram and N. Rajasekar, "A novel flower pollination based global maximum power point method for solar maximum power point tracking," IEEE Transactions on Power Electronics, vol. 32, no. 11, pp. 8486-8499, 2017.

[52] W. Li, G. Zhang, T. Pan, Z. Zhang, Y. Geng, and J. Wang, "A Lipschitz optimization-based MPPT algorithm for photovoltaic system under partial shading condition," IEEE Access, vol. 7, pp. 126323-126333, 2019.

[53] C. González-Castaño, C. Restrepo, S. Kouro, and J. Rodriguez, "MPPT algorithm based on artificial bee colony for PV system," IEEE Access, vol. 9, pp. 43121-43133, 2021.

[54] J. Ahmed, Z. Salam, M. Kermadi, H. N. Afrouzi, and R. H. Ashique, "A skipping adaptive P\&O MPPT for fast and efficient tracking under partial shading in PV arrays," International Transactions on Electrical Energy Systems, vol. 31, no. 9, pp. 1-23, 2021. 